\title{
ASSESSMENT OF RISK FACTORS AND QUALITY OF LIFE AMONG NURSES WITH VARICOSE VEINS AT TERTIARY HEALTH CARE HOSPITALS, CHENNAI
}

\author{
Mrs. Savithri K.B.* I Dr. Raj Rani**
}

*Associate Professor, Panimalar College Of Nursing, Chennai, Tamil Nadu, India.

**Principal, GTB, Jandiala Guru, Amritsar, Punjab, India.

ABSTRACT

DOI: http://doi.org/10.47211/idcij.2020.v07iws02.006

Background: Work-related health problems are common among nurses. There are various work-related health problems among them low back pain, hypertension and Varicose vein are most evident. High prevalence of varicose veins and its complications is an emerging problem in the twenty-first century. This study aimed to determine the associated risk factors and quality of life (QoL) among nurses with varicose veins.

Methods: Cross-sectional study was conducted in October and November 2018 among 96 nurses working in tertiary health care hospitals. Standard physical examination was used to check the condition of varicose veins in the lower extremities of participants. Data collected by using structured interview with the tool, Ware et al. (1993) RAND- 36 Item Short Form Health Survey (SF-36) for Quality of life (QoL) and background variables

Results: Varicose veins were significantly associated with age family history of varicose disease, blood pressure and long standing. The results of the study depicted that $78 \%$ patients had poor QoL. The mean percentage of composite summaries of QoL was low QoL in all its spheres. A statistically significant association was noted between the mean score of QoL and type of exercise at $p<.0001$.

Conclusions: Varicose veins were associated with risk factors such as increasing age, family history of varicose disease, high blood Pressure, and prolonged standing. The present study makes evident that majority of the nurses with varicose vein has poor QoL and it affects all dimensions of QoL.

Key Words: Quality of life, RAND-36, varicose veins, risk factors.

\section{ABOUT AUTHORS:}

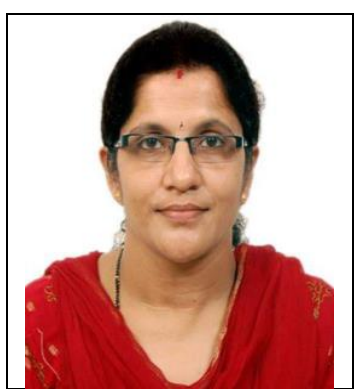

Author, Mrs. Savithri K.B is Associate Professor, Panimalar College of Nursing, Chennai, Tamil Nadu, India.

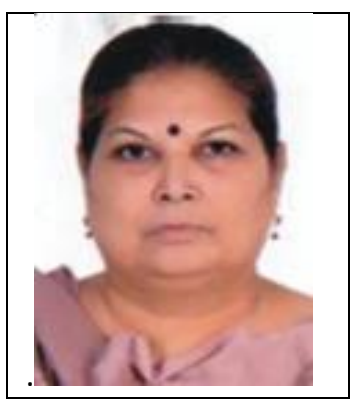

Author, Dr. Raj Rani is Principal, GTB, Jandiala Guru, Amritsar, Punjab, India. She has published papers in international and national Journals. 


\section{INTRODUCTION}

Nurses are a necessary part of medicinal services conveyance framework. In releasing the obligations, nurses experience an assortment of occupational related medical issues, which might be arranged into biological hazards, physical hazards and psychological hazards.

Diseases are more common in the world; the individual will discover the reason for illnesses. Prompt awareness is the most ideal approach to spare the life effectively. Varicose veins are one of the chief preventable infections which are related with veins. It is a serious disease, which presents danger to life of patient when successful and effective measures are not taken ${ }^{1}$

\section{OBJECTIVES}

1. To assess the risk factors and quality of life among nurses with varicose veins

2. To associate risk factors with occurrence of varicose veins among nurses

3. To associate quality of life with selected demographic variables of nurses with varicose veins.

\section{NEED OF THE STUDY}

Varicose veins is the most widely recognized illness in ladies and in individuals whose occupations require delayed standing, pregnancy, nurses, educators, traffic police, security, transport conductors, machine labourers, pregnancy and development labourers and so $\mathrm{on}^{2}$. They are at higher risk of developing varicose vein because of their inclination of employment which requires prolonged standing at patient bedside and this expansion their danger of getting varicose vein later in their life ${ }^{3}$.

Varicose vein is extending around the world. Since the nurses invest most of the energy standing, they are inclined to get lower appendage side effects which may prompt shallow swollen veins and later create varicose veins ${ }^{4}$. So there is a need to instruct the nurses in regards to this condition so as to forestall it.

\section{REVIEW OF LITERATURE}

A cross-sectional study was led to decide the connection among occupational and demographic hazards that portray varicose veins in the legs and their force among nurses from three general emergency clinics in Amol, Iran. 203 nurses were selected for the examination' and data was gathered through a self-filled questionnaire. The factors deciding the occupational hazard factors on varicose vein which could be interventional in improving the working nurse's condition and personal satisfaction for their drawn out profession ${ }^{4}$.

Regarding gender, majority of the nurses both internationally and in India are female. In UK, Male female ratio among nurses is 1:10. In Canada it is 1:19. In India it is around 1:6 and in case of nursing students in India, 1:3. When considering the age, with advanced age, the risk of getting varicose veins is increased and the male female ratio among aged nurses is 1 in 100. The above said statistical values when combined with other demographic factors, it is evidenced that aged nurses are at high risk of developing varicose veins ${ }^{5}$.

Nurses are at a danger of developing varicose vein, since their work is to represent longer length of time for giving care to the patients, where they have lack of rest to their legs nor practice by which they get inclined to the ailment. Subsequently the personal satisfaction gets influenced and the nurses can't give their $100 \%$ at work $^{5}$. Nurses are in a pivotal need of a counteraction of this ailment on the grounds that intentionally or by ignoring it might additionally prompt entanglements which can be evaded at a prior stage by giving knowledge of prevention of varicose veins ${ }^{6}$.

There is a need to educate the nurses regarding this condition in order to prevent it. Hence the investigator motivated to take up the present study to find out the quality of life and risk factors of varicose veins to prevent its complication

\section{METHODOLOGY}

A descriptive cross-sectional study was conducted in October and November 2018 among nurses working in tertiary Care hospitals in Chennai. Convenient sampling technique was used to select 96 participants. Informed consent was obtained from the participants who full filled the eligibility criteria. A structured self-administered questionnaire and SF-36 questionnaire was used. Demographic data section consists age, gender, education, marital status, personal habits and experience. Risk factors: body mass index (BMI), number of pregnancies, family history of varicose veins, hypertension, oral contraceptive pill (OCP), constipation and duration of standing ${ }^{6}$. Quality of Life: The SF-36 questionnaire is used for self-reported health assessment. It comprises 11 questions with 36 statements that allow determining 8 components in 2 domains: physical (Physical Component Summary, PCS) and mental (Mental Component Summary, MCS). The higher the score the better the quality of life ${ }^{7}$.

In this study, standard physical examination (observational method) was used to check the condition of varicose veins of the lower extremities of participants. Thus, the participants were asked to be standing up for at least 10 minutes, in a way that the body weight is transferred on both lower extremities and classified into none, mild, moderate and severe ${ }^{5}$. 


\section{ARTICLES}

Data management and analysis: Data were entered into Epi-data 3.1 software and then exported to SPSS (Statistical Package for Social Sciences) version 20 for analysis. Descriptive statistics were calculated through cross-tabulation.

RESULTS

Table 1: Frequency and percentage distribution of demographic variables of the Nurses with varicose veins $\mathrm{N}=96$

\begin{tabular}{|c|c|c|c|}
\hline S.No. & Demographic Variables & Frequency & Percentage \\
\hline \multirow[t]{3}{*}{1} & Age in Years & & \\
\hline & $<30$ & 32 & $33 \%$ \\
\hline & $>30$ & 64 & $67 \%$ \\
\hline \multirow[t]{3}{*}{2} & Gender & & \\
\hline & Male & 20 & $21 \%$ \\
\hline & Female & 76 & $79 \%$ \\
\hline \multirow[t]{3}{*}{3} & Educational qualification & & \\
\hline & Graduate & 70 & $73 \%$ \\
\hline & Post-graduate & 26 & $27 \%$ \\
\hline \multirow[t]{5}{*}{4} & Marital Status & & \\
\hline & Married & 53 & $54 \%$ \\
\hline & Unmarried & 27 & $28 \%$ \\
\hline & Widow/widower & 10 & $11 \%$ \\
\hline & Divorced & 06 & $7 \%$ \\
\hline \multirow[t]{5}{*}{6} & Personal Habits & & \\
\hline & Alcohol & 12 & $13 \%$ \\
\hline & Smoking & 05 & $5 \%$ \\
\hline & Both & 04 & $4 \%$ \\
\hline & None & 75 & $78 \%$ \\
\hline \multirow[t]{3}{*}{7} & Diet & & \\
\hline & Mixed & 76 & $79 \%$ \\
\hline & Vegetarian & 20 & $21 \%$ \\
\hline \multirow[t]{4}{*}{8} & Experience & & \\
\hline & $<10$ years & 20 & $21 \%$ \\
\hline & 10-20years & 34 & $35 \%$ \\
\hline & >20years & 42 & $44 \%$ \\
\hline
\end{tabular}

Frequency and percentage distribution of demographic variables

Table No 1 shows demographic variables of the respodents. Based on their age $67 \%$ of them were $>30$ years, $79 \%$ were females, $73 \%$ were graduates and $54 \%$ of them were married. Considering the personal habits, $78 \%$ of them were did not have any bad habits, (79\%) were having Mixed diet and $(44 \%)$ were had $>20$ years of experience. 


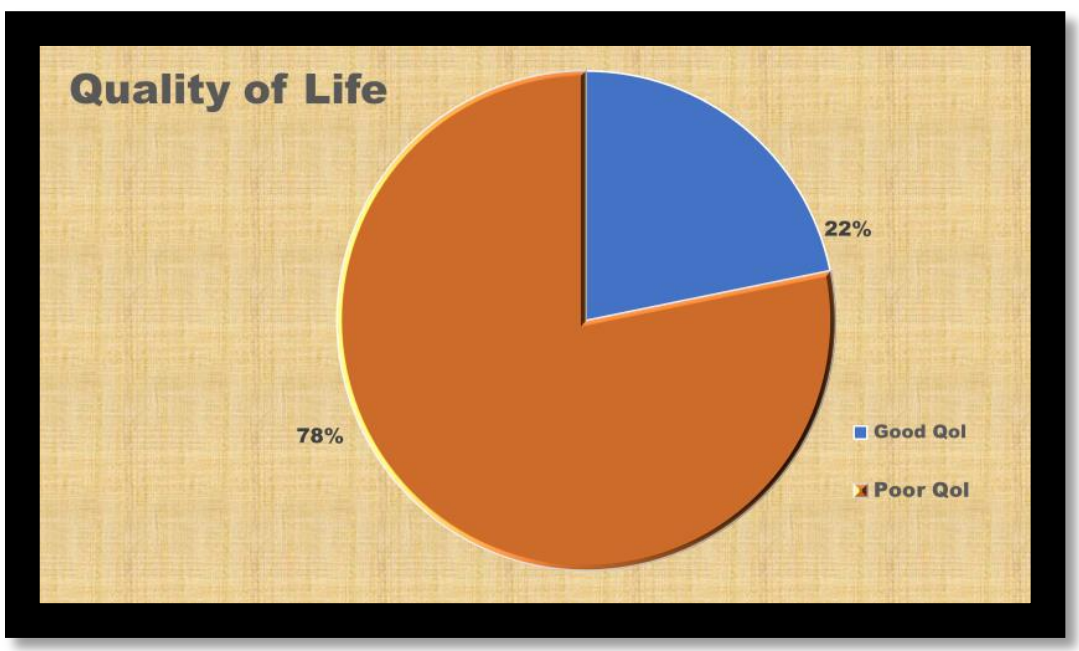

Fig 1: Quality of life (QoL) of nurses with varicose veins

Figure No.1 Majority of the nurses (78\%) had poor QoL

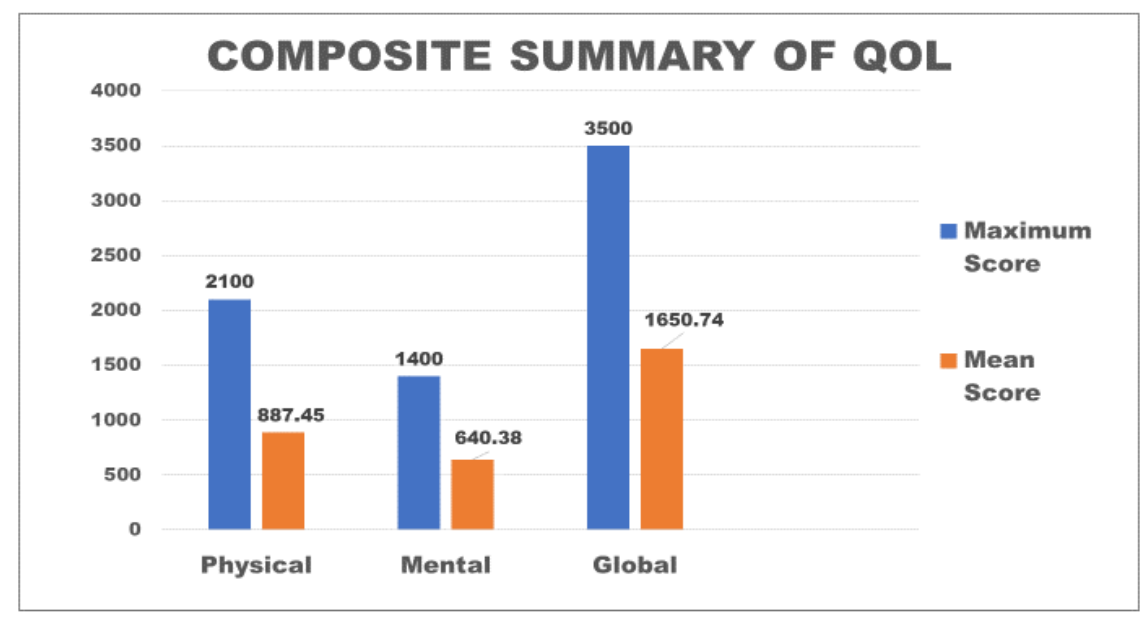

Fig 2 Mean Scores of composite summary of QoL ( $N=96)$

Figure No.2 shows the mean percentage of composite summaries of QoL was low in all its spheres.

Table 2 Mean Scores of Dimensions of QoL ( $N=96)$

\begin{tabular}{lllll}
\hline Dimensions of QoL & $\begin{array}{l}\text { Maximum } \\
\text { Score }\end{array}$ & Mean & SD & Mean Percentage \\
\hline $\begin{array}{llll}\text { Physical Function } \\
\text { Physical Role }\end{array}$ & 1000 & 446.67 & 317.103 & 44.66 \\
Body Pain & 400 & 187.52 & 99.481 & 46.88 \\
General Health & 200 & 69.54 & 35.642 & 34.77 \\
Emotional Role & 500 & 223.96 & 58.373 & 44.79 \\
Vitality & 300 & 153.33 & 73.281 & 51.11 \\
Mental Health & 400 & 193.33 & 68.862 & 48.33 \\
Social Function & 500 & 236.51 & 87.898 & 47.3 \\
\hline Overall & 200 & 99.88 & 43.461 & 49.94 \\
\hline
\end{tabular}

Table. 2 shows the data on dimensions of QoL depicted a higher mean percentage score in emotional role (51.11\%), general health (44.79\%), and lowest mean percentage body pain dimension (34.77\%). 
Table 3: Association of Risk Factors with Varicose Veins $\mathrm{N}=96$

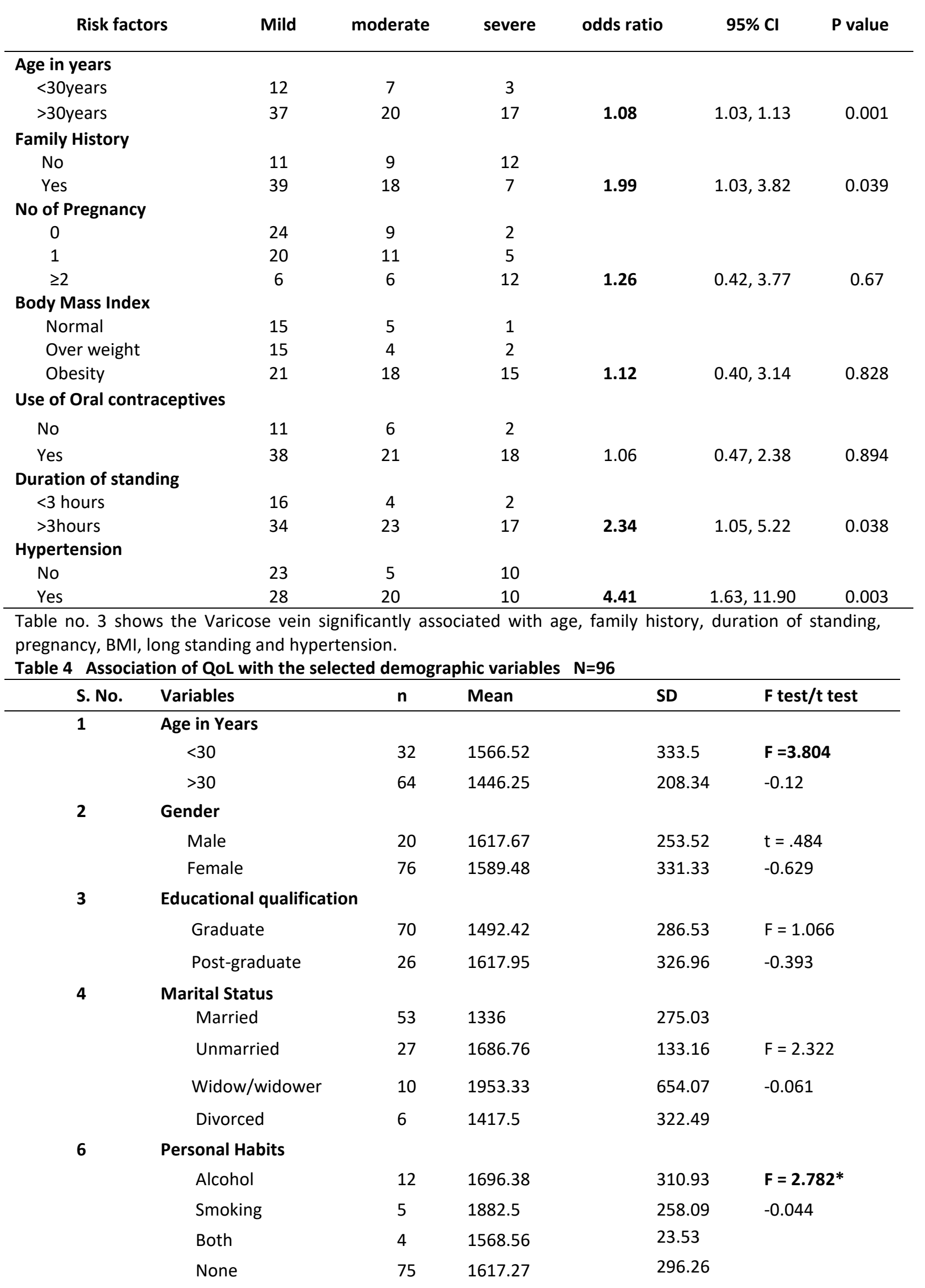




\begin{tabular}{llllll}
\hline S. No. & Variables & $\mathbf{n}$ & Mean & SD & F test/t test \\
\hline $\mathbf{7}$ & Diet & & & & \\
& Mixed & 76 & 1614.91 & 281.49 & $\mathrm{t}=.505$ \\
& Vegetarian & 20 & 1586.62 & 325.05 & -0.615 \\
& Experience & & & \\
& $<10$ years & 20 & 1574.69 & 292.55 & $\mathrm{~F}=.447$ \\
& 10-20years & 34 & 1631.12 & 252.25 & -0.641 \\
& $>$ 20years & 42 & 1584.77 & 426.41 & \\
\hline
\end{tabular}

Table No. 4 shows statistically significant association between the QoL and demographic variables gender and personal habits at $p<0.001$.

\section{DISCUSSION}

This study was done to seek a better knowledge regarding associated risk factors QoL of nurses with varicose veins. In this study increasing age (67\%) was associated with higher chance of developing varicose veins. The results were similar to the studies in this field ${ }^{3,5}$. Increasing BMI was significantly associated with an increase in the prevalence of varicose veins. Many studies have reported obesity and weight gain as known risk factors ${ }^{8}$.

The association between number of pregnancies and risk of varicose veins. Most of the studies reported pregnancy as a known risk factor for varicose veins ${ }^{9,11}$. Risk of varicose veins in individuals with family history (73\%) was more than the risk for people without the family history was consistence with Studies have reported family history as a risk factor for varicose vain ${ }^{3,10}$. Higher blood pressure was significantly associated with the higher odds of lower limb varicose veins. Some studies reported hypertension as a risk of varicose veins ${ }^{10}$.

In this study analysis revealed no significant correlation between the use of oral contraceptives and the risk of varicose veins. A small number of studies have examined the relationship between OCP and varicose veins, and they reported no association or negative association between OCP and risk of varicose veins ${ }^{11}$.

The results showed that increasing hours of standing increased the risk of varicose veins. Many studies have indicated the prolonged standing or sitting as known risk factor for the risk of lower extremity varicose veins5,12. Prolong standing was found to be one of the major risk factors of varicose veins and was seen in $44 \%$, similar findings were observed ${ }^{13}$.

Regarding the association between the QoL and demographic variables age and personal habits there was significant association. This deleterious effect of varicose veins on health has been measured in the past ${ }^{14}$, but it is slightly different to the findings ${ }^{15}$, who found that the deleterious effect was seen only in the domains of "pain" and "general health." A follow-up".

\section{RECOMMENDATION}

1. Health education programs should be implemented for increasing awareness of nurses to prevent varicose vein and its consequences.

2. Further researches; by using a greater sample size, for better generalization.

\section{NURSING IMPLICATION}

Nursing Practice: The present study shows that many suffer varicose vein and their QoL is poor. The nurses can be encouraged to go for screening and help the them to manage and prevent in its early stages.

Nursing Education: The nursing curriculum should include topics on various dimensions of QoL pertaining to occupational health hazards, thereby ensuring adequate knowledge provision on QoL and its application.

Nursing Administration: Nurse Administrator can initiate conduction of screening camps and teaching programs for nurses regarding occupational health hazards, assessment of quality of life and measures to improve quality of life.

Nursing Research: The study findings showed that most of the patients had poor QoL. Similar research studies with a large sample size for better generalization

\section{CONCLUSIONS}

This study showed the significant association between varicose veins and some of the risk factors such as age, blood pressure, family history and prolonged standing. Among modifiable risk factors, tobacco and smoking in any form should be abandoned in order to decrease the incidence of varicose veins. 


\section{REFERENCES}

1. Laddha. G Vidyasagar. Sunil R. Bavaskar.et al. (2012) Varicose Veins recent complications in humans. Shri Jagdishprasad Jhabarmal Tiberwala University, Rajasthan. Vol.2.no.2, 885-895

2. Neill R (2005). Standing problem. Hazards Magazine [online]. Aug 10 [cited 2011 Oct 24];

3. Nasiri- Foourg A, Kazemi T, Nakhaii N, Kazemi N. (2005)Lower limb varicose veins and their relationship with risk factors in nurses of the Birjand University of Medical Sciences Hospital's. Journal of Birjand University of Medical Sciences. 12(12):60-70.[Persian]

4. Sharif $\mathrm{Ni}$ aH et al,(2015). Varicose veins of the legs among Nurses: occupational and demographic characteristics, International Journal of Nursing Practice, June 2(3) 313-320.

5. Beebe-Dimmer JL, Pfeifer JR, Engle JS, Schottenfeld D. (2005) The Epidemiology of Chronic Venous Insufficiency and Varicose Veins. Ann Epidemiol15(3):175-184

6. Shiksha Sharma et al, (2013) Risk Factors for Varicose Veins, IOSR Journal of Pharmacy and Biological Sciences (IOSR-JPBS) e-ISSN: 2278-3008, p-ISSN: 2319-7676. Volume 7, Issue 5 PP 56-59.

7. J.J. Smith, A.M. Garratt, M. Guest, R.M. Greenhalgh, and A.H. Davies, ( 1999) Evaluating and improving health-related quality of life in patients with varicose veins London and York, United Kingdom

8. Fowkes F, Lee A, Evans C, Allan P, Bradbury A, Ruckley C (2001). Lifestyle risk factors for lower limb venous reflux in the general population: Edinburgh Vein Study. Int J Epidemiol. 30:846-852.

9. Robertson L, Evans C, Fowkes FGR. (2008)Epidemiology of chronic venous disease. Phlebology. 23(3):103-111.

10. Carpentier PH, Maricq HR, Biro C, Poncot-Makinen CO, Franco A.(2004) Prevalence, risk factors, and clinical patterns of chronic venous disorders of lower limbs: a population-based study in France. J Vasc Surg. 40(4):650-659.

11. Hossein Ebrahimi , Farzaneh Amanpour, Nahid Bolbol Haghighi (2015) "Prevalence and Risk Factors of Varicose Veins North-east of Iran JRHS Journal of Research in Health Sciences

12. Bihari I, Tornoci L, Bihari P. (2012) Epidemiological study on varicose veins in Budapest. Phlebology. 27(2):77-81.

13. Winterborn RJ, Foy C, Earnshaw JJ. (2004)Causes of varicose vein recurrence: Late results of a randomized controlled trial of stripping the long saphenous vein. J Vasc Surg 40:634-9.

14. Garratt AM, Ruta DA, Abdalla MI, Russell IT. (1996) Responsiveness of the SF-36 and a condition specific measure of health outcome for patients with varicose veins. Qual Life Res; 5:1-12.

15. Baker DM, Turnbull NB, Pearson JC, Makin GS.(1995) A patient outcome study following varicose vein surgery using the SF-36 health assessment questionnaire. Eur J Vasc Endovasc Surg ;9:299-304

16. Brunner and Suddarth's (2014).Text book of Medical Surgical Nursing. Volume I.13th edition. Philadelphia: Wolter Kluwer publications. 